\title{
Malignant Solitary Fibrous Tumor of the Nasal Cavity
}

\author{
Daniel M. Zeitler, M.D., ${ }^{1,2}$ Seth J. Kanowitz, M.D., ${ }^{1,2}$ and Gady Har-EI, M.D., ${ }^{2,3,4}$
}

Solitary fibrous tumors (SFTs) are unusual mesenchymal tumors that were first described as primary spindle-cell neoplasms of the pleura. These tumors have been described in many other locations, including the urogenital system, orbit, mediastinum, and upper respiratory tract. Twenty-two cases of an SFT of the paranasal sinuses and nasal cavity have been reported, but none described a malignant SFT extending through the anterior skull base. A 70-year-old man had a 6-month history of unilateral left-sided epiphora and nasal obstruction. Computed tomography and magnetic resonance imaging showed a large left-sided nasal cavity mass with extension into the left extraconal orbit and intracranial extension through the left cribriform plate and ethmoid roof. The patient underwent preoperative embolization of the internal maxillary artery and a subsequent anterior craniofacial resection via a midfacial degloving approach and a left anterior craniotomy. Histopathological analysis of the specimen was consistent with a malignant SFT.

KEYWORDS: Solitary fibrous tumor, midfacial degloving, anterior skull base, nasal cavity, immunohistochemistry

In 1931 Klemperer and Rabin first described solitary fibrous tumors (SFTs) as distinct mesothelial tumors arising from the pleura. ${ }^{1}$ Due to their proposed origin, these tumors have been known by other names, including benign fibrous mesotheliomas and submesothelial fibromas. The true nature of these tumors has long been debated, and most investigators now believe that their origin is mesenchymal, as evidenced by their fibroblastic differentiation seen histopathologically. ${ }^{2}$ This fact helps explain the finding of SFTs in extrapleural sites such as the meninges, orbit, peritoneum, pelvis, adrenal glands, liver, and urogenital system. ${ }^{3-5} \mathrm{Re}-$ cently, SFTs have also been reported in the head
${ }^{1}$ Department of Otolaryngology, New York University School of Medicine, New York, New York; ${ }^{2}$ Department of OtolaryngologyHead and Neck Surgery, Lenox Hill Hospital, New York, New York; ${ }^{3}$ Department of Otolaryngology, ${ }^{4}$ Department of Neurosurgery, State University of New York-Downstate University, New York, New York.

Address for correspondence and reprint requests: Daniel M. Zeitler, M.D., 550 First Ave., New Bellevue 5 East 5, New York,
NY 10016 (e-mail: dmz206@med.nyu.edu).

Skull Base 2007;17:239-246. Copyright (C) 2007 by Thieme Medical Publishers, Inc., 333 Seventh Avenue, New York, NY 10001, USA. Tel: +1(212) 584-4662.

Received: May 24, 2006. Accepted after revision: July 17, 2006. Published online: July 17, 2007.

DOI 10.1055/s-2007-984489. ISSN 1531-5010. 
and neck region, located in such subsites as the larynx, ${ }^{6}$ hypopharynx, ${ }^{7}$ thyroid gland, ${ }^{8}$ parapharyngeal space, ${ }^{9}$ and tongue. ${ }^{10}$ SFTs of the nasal cavity and paranasal sinuses are extremely rare; only 22 cases have been reported. When a malignant SFT is encountered, adequate resection with negative margins is paramount for successful therapy. We report an extremely rare malignant SFT of the nasal cavity and paranasal sinuses successfully treated by anterior craniofacial resection through a midfacial degloving approach.

\section{CASE REPORT}

A 70-year-old man had a 6-month history of slowly progressive unilateral left-sided nasal and periorbital swelling and nasal obstruction. He also reported the recent onset of increasing left epiphora, but he denied diplopia or changes in visual acuity. His medical history was significant for hypertension, asthma, and chronic obstructive pulmonary disease. $\mathrm{He}$ denied a history of tobacco or alcohol use. $\mathrm{He}$ denied chronic or recent episodes of sinusitis.

A thorough cranial nerve examination was unremarkable as was the remainder of his head and neck examination. Rigid nasal endoscopy showed a large, well-circumscribed mass filling the left nasal cavity with an apparent origin from the superior meatus. There was no evidence of mucopus or polyps, and the right nasal cavity and nasopharynx appeared normal.

Gadolinium-enhanced magnetic resonance imaging (MRI) of the brain (Fig. 1) and computed tomography (CT) of the paranasal sinuses (Fig. 2) showed a large, expansile mass in the left nasal cavity with extension into the inferomedial extraconal space of the left orbit and into the left maxillary sinus. The mass also extended through the cribriform plate and was associated with intracranial enhancement in the left subfrontal region. There was postobstructive opacification of the ethmoid, sphenoid, and frontal sinuses on the left side. Endoscopic biopsy showed a spindle-cell neoplasm

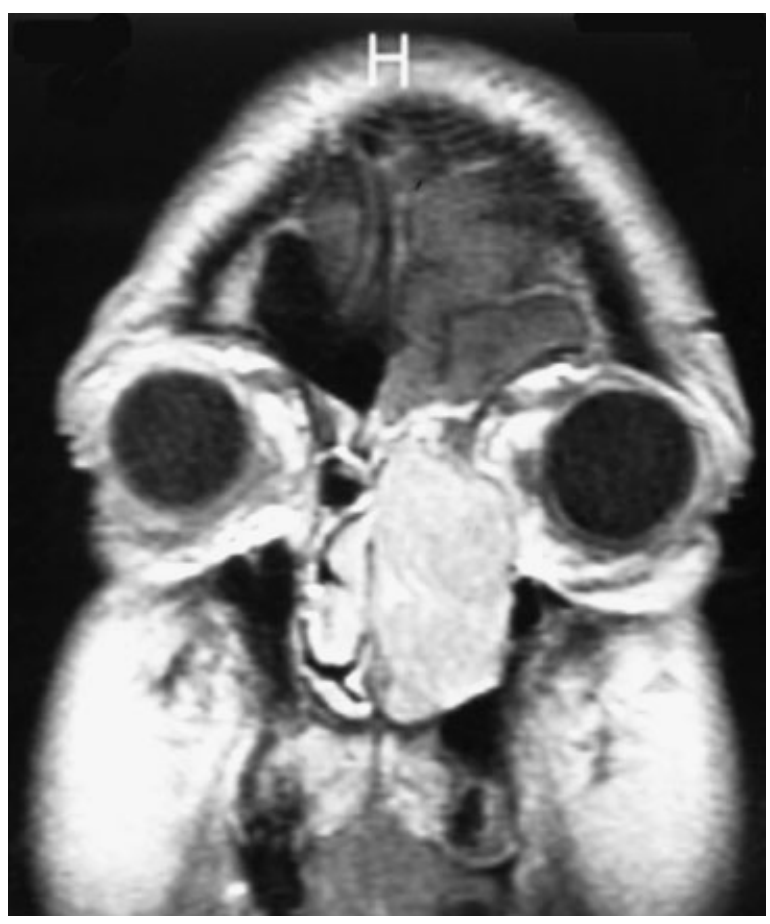

Figure 1 T1-weighted gadolinium-enhanced MRI shows the presence of a large left nasal mass abutting the left periorbita and extending into the anterior cranial fossa with dural enhancement.

with atypical features. Immunoreactivity for CD34 and bcl-2 confirmed the diagnosis of an SFT.

Preoperatively, head and neck angiography showed a vascular tumor supplied by the sphenopalatine artery and by the anterior and posterior ethmoid arteries. The left internal maxillary artery was embolized. Postembolization angiography confirmed complete elimination of all vascular supply to the tumor.

Next, the patient underwent an anterior craniofacial resection via a midfacial degloving approach as described elsewhere. ${ }^{11}$ Intraoperative findings included partial erosion of the left medial orbital wall, lacrimal bone, frontal process of the maxilla, and lateral aspect of the left nasal bone. The periorbita remained intact. A left-sided anterior craniotomy was performed and showed a subfrontal skull base defect in the area of the cribriform plate extending laterally to the fovea ethmoidalis. No gross dural invasion was appreciated on inspection, and frozen 

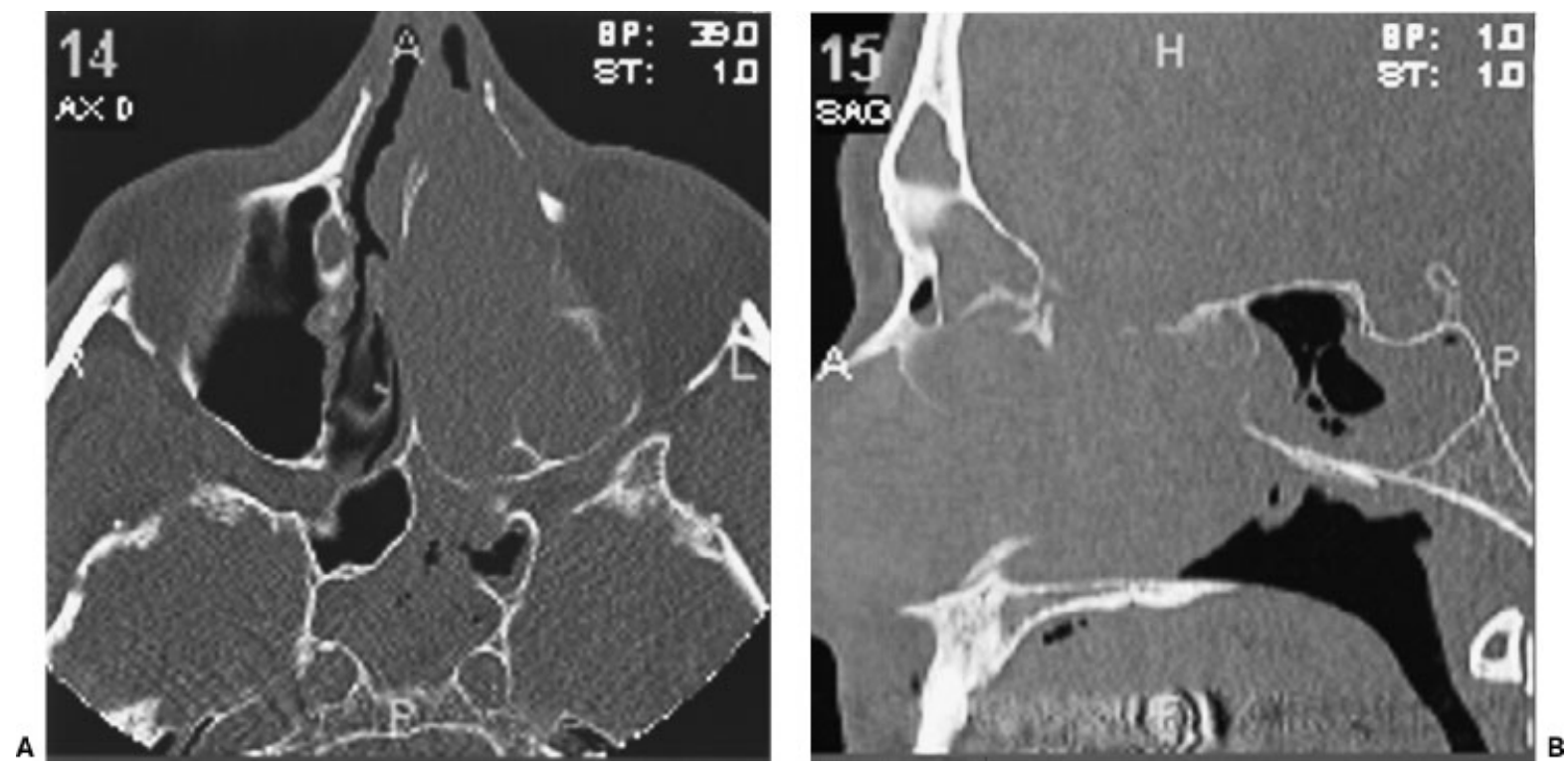

Figure 2 (A) Axial and (B) sagittal CT scans show the presence of a large mass filling the left nasal cavity with erosion of the lateral nasal wall, nasolacrimal duct, nasal septum, and anterior skull base with postobstructive fluid in the sphenoid sinus.
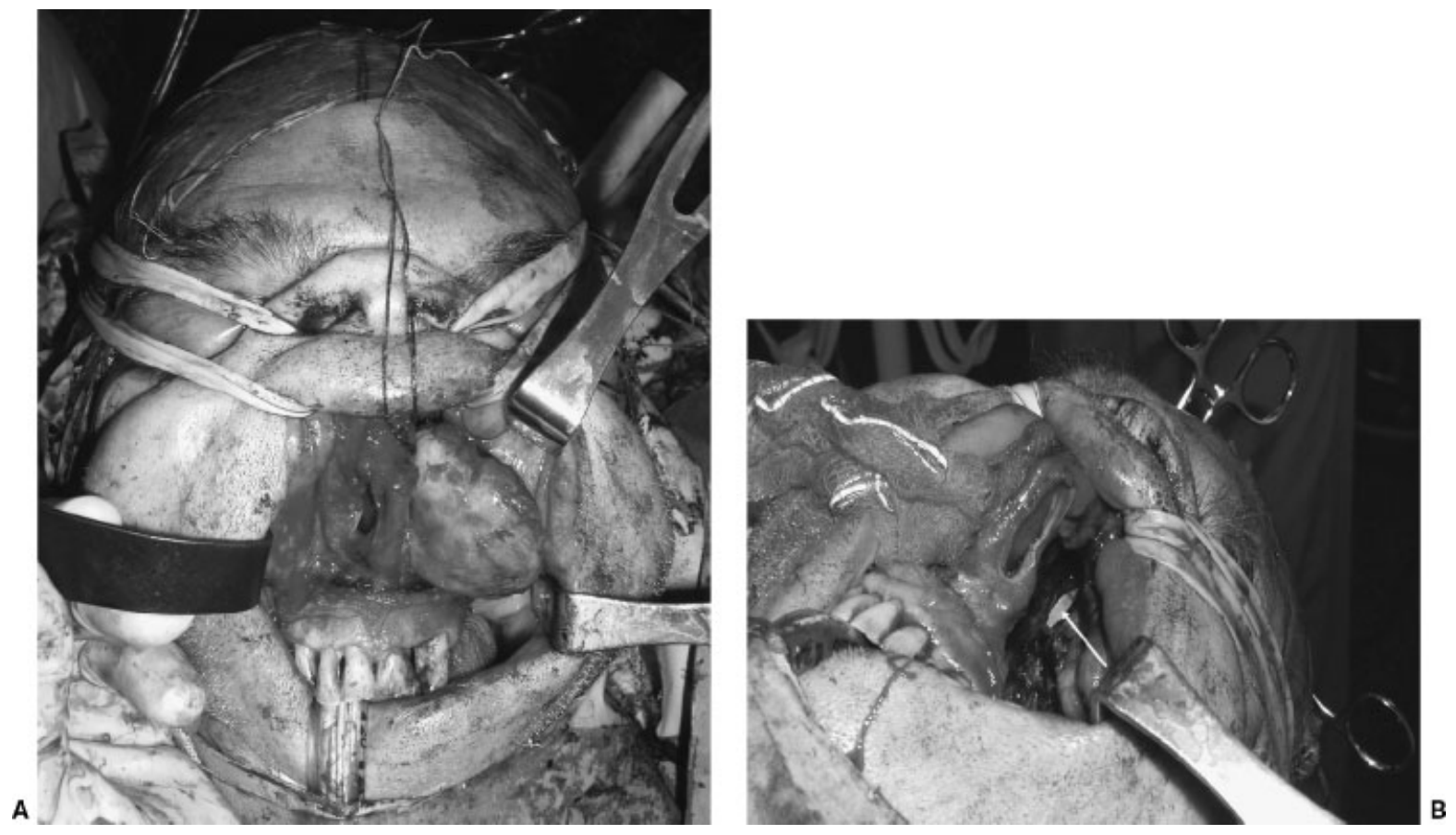

Figure 3 (A) The well-encapsulated tumor is being removed from the left nasal cavity via the midfacial degloving approach. (B) After the tumor is removed, the associated skull base defect is identified by the presence of blue plastic sheeting (white arrow) placed intracranially during the craniotomy. 
section biopsies in the region of the ethmoid roof defect were negative for tumor invasion.

Sterile blue plastic sheeting from a Mayo stand cover was used to line the anterior cranial fossa in the area of the skull base defect. The tumor was removed en bloc with minimal bleeding, and all other vital structures were preserved (Fig. 3A). Intranasally, the tumor was well encapsulated. Dissection from the nasal cavity proceeded superiorly until the blue plastic material, which identified the skull base defect, was seen (Fig. 3B). The blue plastic material was removed, and the frontal sinuses were obliterated with bone cement. Subequently, the skull base defect was reconstructed with a pericranial flap.

Pathological examination revealed a 6.5$\times 4.2-\times 2.5-\mathrm{cm}$ malignant SFT. Light microscopy showed a high mitotic rate ( $>10$ mitoses $/ 10$ highpowered fields $[\mathrm{HPF}]$ ), a focal bizarre giant cell component, and bony involvement of the inferior turbinate. Focal areas of necrosis were present within the surgical specimen. All surgical margins were negative for disease. Immunohistochemical studies were positive for vimentin, CD34, bcl-2, and CD99. Desmin, S-100, and human chorionic gonadotropin (HCG) stains were negative.

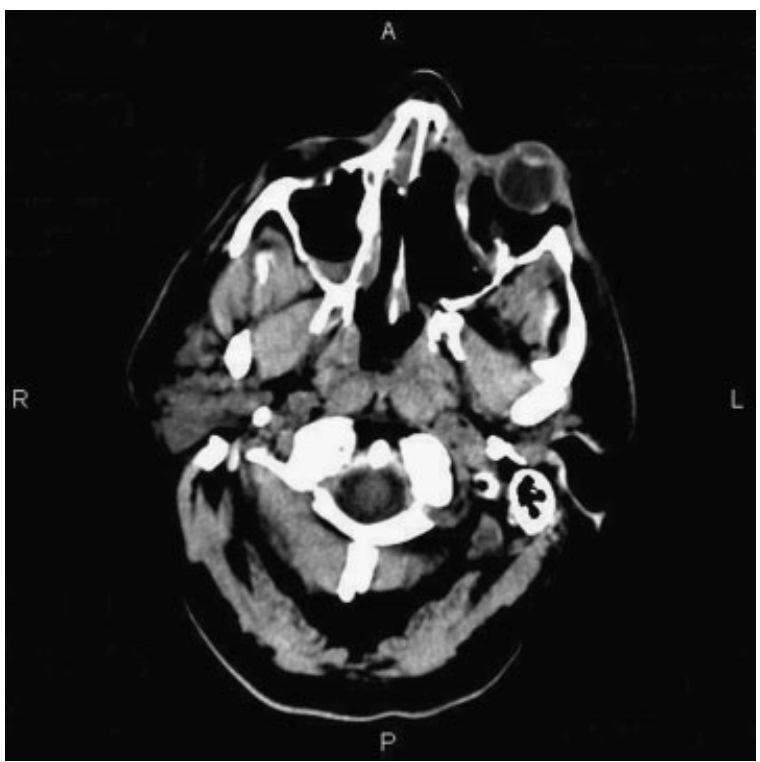

Figure 4 Postoperative axial CT scan confirms complete excision of the left-sided nasal cavity mass.
Postoperative CT showed no evidence of residual tumor (Fig. 4). After surgical extirpation of the SFT, the patient was scheduled to undergo external beam radiation therapy. Unfortunately, adenocarcinoma of the colon was diagnosed 5 weeks after the anterior craniofacial resection. The patient underwent radical colectomy but died of postoperative complications at an outside institution.

\section{DISCUSSION}

SFTs are uncommon neoplasms that were originally described as arising from mesothelial cells exclusively within the thoracic cavity. ${ }^{1}$ Immunohistochemical studies and electron microscopy have since helped identify the neoplastic cells as undifferentiated mesenchymal cells with no evidence of mesothelial or epithelial differentiation. The mesenchymal rather than mesothelial origin of the tumors is further supported by the growth of this tumor in numerous extraserosal sites. Interestingly, extrathoracic SFTs appear to have histological, immunohistochemical, and ultrastructural features similar to those described for tumors arising from the pleura-based intrathoracic regions. ${ }^{12}$

Of the extrathoracic SFTs reported in the English literature over the last several decades, the preferred sites seem to be within the head and neck region, including the larynx, ${ }^{6}$ hypopharynx, ${ }^{7}$ parapharyngeal space, ${ }^{9}$ tongue, ${ }^{10}$ orbit, ${ }^{13}$ and paranasal sinuses and nasal cavity. ${ }^{14}$ Much like their intrathoracic counterparts, extrathoracic head and neck SFTs tend to behave in a benign fashion. ${ }^{15}$ Authors have described "malignant" extrathoracic SFTs. In most cases, however, the term refers to atypical histologic features, including nuclear atypia, increased cellularity, necrosis, and more than 4 mitoses per $10 \mathrm{HPF}$, and not to the clinical behavior of the tumor. ${ }^{16}$ Approximately 10 to $15 \%$ of SFTs located outside the thoracic cavity are recurrent or metastatic. In addition, a small percentage of histologically benign tumors demonstrates clinically malignant 
behavior. ${ }^{5}$ However, no nasal SFT has been reported to recur or metastasize.

In a review of the literature, Alobid et al describe 21 cases of a primary SFT arising in the nasal cavity and paranasal sinuses. ${ }^{17}$ Most patients in this series sought treatment for complaints of a unilateral mass, nasal obstruction, rhinorrhea, epistaxis, and/or exophthalmos. ${ }^{17}$ Other signs and symptoms, such as epiphora, anosmia, headache, facial pain, and visual disturbances, can also be present. On CT, SFTs of the nasal cavity and paranasal sinuses classically show irregular central bone density due to remodeled and reactive native bone; on T2-weighted MRI, the soft-tissue component of SFTs is iso- to hypointense. ${ }^{18}$

Pathological diagnosis of SFTs can be difficult because these tumors express various histologic features that mimic those found in other soft-tissue neoplasms such as hemangiopericytomas, schwannomas, fibrous histiocytomas, fibrosarcomas, and nasopharyngeal angiofibromas. ${ }^{19}$ Macroscopically, SFTs are well-circumscribed, tan, rubbery masses often tethered by a pedicle. Microscopically, these neoplasms are described as "patternless" with a haphazard arrangement of bland-appearing spindle cells, hypercellular and hypocellular sclerotic foci, stromal hyalinization, and a prominent branching vasculature. $^{12}$

Immunohistochemistry is the key to the correct diagnosis of SFTs. Almost all tumors exhibit strong immunoreactivity for CD34, a myeloid progenitor cell antigen. ${ }^{2,12,20}$ In addition, $75 \%$ of the tumors examined by Hasegawa and colleagues were diffusely reactive for bcl-2 protein. ${ }^{12}$ Other common markers include CD99 and vimentin. Classically, these tumors show negative staining for keratin, epithelial membrane antigen, S-100, glial fibrillary acidic protein, and carcinoembryonic antigen, further highlighting their mesenchymal origin. ${ }^{21}$

Resectability is the most important prognostic factor; therefore, effective treatment of SFTs of the nasal cavity and paranasal sinuses involves en bloc surgical excision. ${ }^{18,22}$ Previously reported cases of SFTs in the nasal cavity and paranasal sinuses have been removed using a variety of surgical techniques, including local excision, medial maxillectomy, external ethmoidectomy, endoscopic resection, and sphenoidectomy. ${ }^{23}$ Only two cases of skull base SFTs have been reported, and these tumors were removed through a transcranial approach $^{24}$ and an open transfacial approach, respectively. ${ }^{18}$

The classic anterior craniofacial resection positively affects the treatment of such tumors. ${ }^{25}$ Midfacial degloving, a modification of the anterior craniofacial resection, improves surgical exposure, reduces complication rates, extends tumor resectability, and improves cosmesis. This technique provides excellent exposure of both nasal cavities, ethmoid complexes, maxillary sinuses, and the anterior skull base. ${ }^{26}$ Therefore, it is especially suited for bilateral, bulky, or malignant disease in which negative margins are mandated. Given the malignant behavior of our patient's tumor and the lack of involvement of the pterygopalatine fossa, midfacial degloving provided excellent exposure and allowed us to achieve negative margins in all surgical dimensions.

In conclusion, we present a rare case of a malignant SFT of the nasal cavity removed using anterior craniofacial resection via a midfacial degloving approach. This case highlights the importance of recognizing SFTs as uncommon tumors of the nasal cavity and paranasal sinuses with the capability to invade the skull base. SFTs therefore should be included as part of the differential diagnosis of such presentations. This case also stresses the important distinction between the histopathology and clinical behavior of SFTs, emphasizing that malignant pathology does not imply malignant behavior.

\section{ACKNOWLEDGMENTS}

The authors thank Elana Opher, M.D., for her surgical pathology consultation and Fariborz Nobandegani, M.D., for his neurosurgical consultation and assistance during the case. 


\section{REFERENCES}

1. Klemperer P, Rabin CB. Primary neoplasms of the pleura. Arch Pathol (Chic) 1931;11:385-412

2. Hanau CA, Miettinen M. Solitary fibrous tumor: histological and immunohistochemical spectrum of benign and malignant variants presenting at different sites. Hum Pathol 1995;26:440-449

3. Morimitsu Y, Nakajima M, Hisaoka M, et al. Extrapleural solitary fibrous tumor: clinicopathologic study of 17 cases and molecular analysis of the p53 pathway. APMIS 2000; 108:617-625

4. Barnoud R, Arvieux C, Pasquier D, Pasquier B, Letoublon C. Solitary fibrous tumour of the liver with CD34 expression. Histopathology 1996;28:551-554

5. Vallat-Decouvelaere AV, Dry SM, Fletcher C. Atypical and malignant solitary fibrous tumors in extrathoracic locations: evidence of their comparability to intra-thoracic tumors. Am J Surg Pathol 1998;22:1501-1511

6. Alobid I, Alós L, Maldonado M, Menéndez LM, BernalSprekelsen M. Laryngeal solitary fibrous tumor treated with $\mathrm{CO}_{2}$ laser excision: case report. Eur Arch Otorhinolaryngol 2005;262:286-288

7. Mussak EN, Jiangling JT, Voigt EP. Malignant solitary fibrous tumor of the hypopharynx with dysphagia. Otolaryngol Head Neck Surg 2005;133:805-807

8. Taccagni G, Sambade C, Nesland J, Terreni MR, Sobrinho-Simoes M. Solitary fibrous tumour of the thyroid: clinicopathological, immunohistochemical and ultrastructural study of three cases. Virchows Archiv A Pathol Anat Histopathol 1993;422:491-497

9. Gangopadhyay K, Taibah K, Manohar MB, Kfoury H. Solitary fibrous tumor of the parapharyngeal space: a case report and review of the literature. Ear Nose Throat J 1996; 75:681-684

10. Shnayder Y, Greenfield BJ, Oweity T, DeLacure MD. Malignant solitary fibrous tumor of the tongue. Am J Otolaryngol 2003;24:246-249

11. Har-El G. Medial maxillectomy via midfacial degloving approach. Oper Tech Otolaryngol Head Neck Surg 1999; 10:82-86

12. Hasegawa T, Matsuno Y, Shimoda T, et al. Extrathoracic solitary fibrous tumors: their histological variability and potentially aggressive behavior. Hum Pathol 1999;30: 1464-1473

13. Gigantelli JW, Kincaid MC, Soparkar CN, et al. Orbital solitary fibrous tumor: radiographic and histopathologic correlations. Ophthal Plast Reconstr Surg 2001;17:207-214

14. Zukerberg LR, Rosenberg AE, Randolph G, Pilch BZ, Goodman ML. Solitary fibrous tumor of the nasal cavity and paranasal sinuses. Am J Surg Pathol 1991;15:126- 130
15. Brunnemann RB, Ro JY, Ordonez NG, Mooney J, El-Naggar A, Ayala AG. Extrapleural solitary fibrous tumor: a clinicopathologic study of 24 cases. Mod Pathol 1999;12:1034-1042

16. Romer M, Bode B, Schuknecht B, Schmid S, Holzmann D. Solitary fibrous tumor of the orbit-two cases and a review of the literature. Eur Arch Otorhinolaryngol 2005; 262:81-88

17. Alobid I, Alós L, Blanch JL, et al. Solitary fibrous tumor of the nasal cavity and paranasal sinuses. Acta Otolaryngol 2003;123:71-74

18. Kim TA, Brunberg JA, Pearson JP, Ross DA. Solitary fibrous tumor of the paranasal sinuses: CT and MR appearance. AJNR Am J Neuroradiol 1996;17:17671772

19. Witkin GB, Rosai J. Solitary fibrous tumor of the upper respiratory tract. A report of six cases. Am J Surg Pathol 1991;15:842-848

20. Westra WH, Gerald WL, Rosai J. Solitary fibrous tumor: consistent CD34 immunoreactivity and occurrence in the orbit. Am J Surg Pathol 1994;18:992-998

21. Kohmura T, Nakashima T, Hasegawa Y, Matsuura H. Solitary fibrous tumor of the paranasal sinuses. Eur Arch Otorhinolaryngol 1999;256:233-236

22. England DM, Hochholzer L, McCarthy MJ. Localized benign and malignant fibrous tumors of the pleura. A clinicopathologic review of 223 cases. Am J Surg Pathol 1989; 13:640-658

23. Kessler A, Lapinsky J, Berenholz L, Sarfaty S, Segal S. Solitary fibrous tumor of the nasal cavity. Otolaryngol Head Neck Surg 1999;121:826-828

24. Hicks DL, Moe KS. Nasal solitary fibrous tumor arising from the anterior cranial fossa. Skull Base 2004;14:203-207

25. Patel SG, Singh B, Polluri A, et al. Craniofacial surgery for malignant skull base tumors: report of an international collaborative study. Cancer 2003;98:1179-1187

26. Har-El G. Anterior craniofacial resection without facial skin incisions-a review. Otolaryngol Head Neck Surg 2004;130:780-787

\section{Commentary}

Zeitler and coworkers report a case of a malignant solitary fibrous tumor of the nasal cavity and paranasal sinuses with extension into the orbit and intracranial space. These rare
${ }^{1}$ Division of Neurological Surgery, Barrow Neurological Institute, St. Joseph's Hospital and Medical Center, Phoenix, Arizona. Skull Base 2007;17:244-245. Copyright (C) 2007 by Thieme Medical Publishers, Inc., 333 Seventh Avenue, New York, NY
10001, USA. Tel: +1(212) 584-4662.

Published online: July 17, 2007.

DOI 10.1055/s-2007-984490. ISSN 1531-5010. 
tumors of mesenchymal origin were originally described in the intrathoracic region but have since been found in many extrathoracic sites, including the head and neck region. The case presented is especially rare in that the histopathology revealed a malignant tumor, and on gross pathology it was found to be an aggressive tumor, having eroded through the anterior skull base. It is unfortunate that the authors are unable to follow this patient clinically to see whether this tumor would have recurred or metastasized, acting in a clinically malignant fashion after complete resection.
We agree that the midfacial degloving approach combined with either a conventional frontal craniotomy or the subcranial approach provides excellent exposure of both nasal cavities, ethmoid complexes, maxillary sinuses, ethmoid roof, cribriform plates, sphenoid sinuses, nasopharynx, and anterior skull base. This approach was an excellent means by which to ensure en bloc resection of this complex tumor with negative margins. Furthermore, this approach offers excellent cosmesis without disfiguring facial incisions.

Elisa J. Beres, M.D. ${ }^{1}$ 
